\title{
Initiation and Cytological Aspects of Somatic Embryogenesis in Dendrobium candidum Wall ex Lindl.
}

\author{
Yihui Cui ${ }^{1}$ \\ School of Life Science and Engineering, Southwest Jiaotong University, \\ Chengdu 610031, People's Republic of China
}

Peng Zhao'

School of Life Science and Engineering, Southwest Jiaotong University, Chengdu 610031, People's Republic of China; and State Key Laboratory of Hybrid Rice, College of Life Sciences, Wuhan University, Wuhan 430072, People's Republic of China

\section{Hongqiang An, Nan Lv, Zifeng Zhang, Wei Pei, and Wanjun Wang ${ }^{2}$ School of Life Science and Engineering, Southwest Jiaotong University, Chengdu 610031, People's Republic of China}

Additional index words. somatic embryogenesis, Dendrobium candidum, orchid, calli

\begin{abstract}
To find the characteristics of somatic embryogenesis of orchids and elucidate the mechanism, we had previously established an efficient plant regeneration system via somatic embryogenesis in Dendrobium candidum Wall ex Lindl. In this study, a detailed cytological investigation was carried out on the initiation and developmental process of somatic embryogenesis. Based on our observations, the somatic embryogenesis in $D$. candidum originated from the transition of an embryonic callus cell to the initial somatic embryo cell, and the somatic embryos initiated from those cells. During the transition process, condensation and devacuolation successively occurred in the cytoplasm of the embryonic callus cells, giving rise to the formation of a typical initial somatic embryo cell with dense cytoplasm and a clear nucleus. One of the two pathways in somatic embryogenesis is the single-cell-derived somatic embryo which is generated from an inner initial somatic embryo cell in embryonic callus and develops into a globular somatic embryo in a way similar to zygotic embryogenesis and then keeps developing into a protocorm-like body (PLB). The other is a multiple-cellderived somatic embryo which is generated from peripheral grouped initial somatic cells in embryonic calli and directly forms globular embryo or multicellular somatic proembryo, lacking the typical early stages of embryogenesis. Both pathways were observed in the somatic embryogenesis system, indicating that the culture system in D. candidum can be a useful tool for investigating the mechanisms underlying orchid embryogenesis.
\end{abstract}

Dendrobium candidum Wall ex Lindl., a monocotyledon belonging to the family Orchidaceae, is distributed in countries of South and Southeast Asia. As an endangered species, mass propagation of this orchid has been actively studied (Shiau et al., 2005; Zhao et al., 2007, 2008), and it is also of interest in the isolation of new medical compounds (Li et al., 2008, 2009a, 2009b). Embryo development in the Orchidaceae differs from that of all other monocotyledons and dicotyledons because embryogeny ceases at very early stage as the endosperm degenerates (Maheswaran and Williams,

Received for publication 15 Dec. 2015. Accepted for publication 10 May 2016.

This work was supported by the Grant (No. 31371232) from the National Natural Science Foundation of the People's Republic of China.

${ }^{1}$ Co-first authors.

${ }^{2}$ Corresponding author. E-mail: wanjunwang@home. swjtu.edu.cn.
1985; Nagmani et al., 1987; Williams and Maheswaran, 1986). Thus, little is known about the process of embryo development in Dendrobium, and somatic embryogenesis may provide an alternative system to study this process in orchids.

Somatic embryogenesis, a regeneration technique effective in plant mass propagation, has been established in many species, e.g., Daucus carota (Lee et al., 2001; Nishiwaki et al., 2000), Oryza sativa L. (Meneses et al., 2005; Raval and Chattoo, 1993), Arabidopsis thaliana (Ikeda-Iwai et al., 2002; Luo and Koop, 1997), Phalaenopsis (Chen and Chang, 2006; Chung et al., 2006), and Cymbidium (Huan et al., 2004). The developmental process of somatic embryogenesis shares considerable similarity with that of zygotic embryogenesis (Zimmerman, 1993) because of the proposed conservation of molecular mechanisms underlying both processes (Higashi et al., 1998). Therefore, it provides us a useful model system for studying embryogenesis, especially in species such as the orchid, in which zygotic embryos are inaccessible.

Although there were a few studies on the zygotic embryogenesis of orchid such as Cymbidium (Huang et al., 1998; Ye and Guo, 1995), Phaius tankervilliae (Ye et al., 1997), and D. candidum (Xu et al., 1995), how somatic embryos are generated in the orchid and how similar the process might be to zygotic embryogenesis remain unclear. We have previously established an efficient somatic embryogenesis system in $D$. candidum, in which new PLBs would be achieved from the embryonic calli (Zhao et al., 2008). In this article, we described the details on the developmental process of somatic embryogenesis and focus on the formation of initial somatic embryo cells and pathways of somatic embryo's origin.

\section{Materials and Methods}

Induction and regeneration of somatic embryo. Mature seeds of $D$. candidum were cultured in an MS medium supplemented with $1.08 \mu \mathrm{M}$ 1-naphthaleneacetic acid. The protocorms, about $3 \mathrm{~mm}$ in diameter, were longitudinally bisected. The calli were induced from longitudinally bisected segments of protocorms and subcultured two times every $40 \mathrm{~d}$ for screening the embryonic calli on a $1 / 2 \mathrm{MS}$ medium supplemented with $8.8 \mu \mathrm{M}$ 6-Benzylaminopurine (Zhao et al., 2008). The embryonic calli were then cultured for the induction of somatic embryos on a modified $1 / 2 \mathrm{MS}$ medium without any plant growth regulators (mMS) under illumination (30-34 $\mu \mathrm{mol} \cdot \mathrm{m}^{-2} \cdot \mathrm{s}^{-1}$ ) with $12-\mathrm{h}$ photoperiod and a temperature of $25 \pm 2{ }^{\circ} \mathrm{C}$.

Histological study of somatic embryo development. The embryonic calli on mmS were fixed in FAA solution (formalin: acetic acid: $70 \%$ ethanol $=1: 1: 18 \mathrm{v} / \mathrm{v} / \mathrm{v}$ ) every day $(0 \sim 40 \mathrm{~d})$, dehydrated in an ethanol series, and embedded in paraffin wax. The embedded materials were sectioned to a thickness of $8 \mu \mathrm{m}$ with a Microtome QPJ-1B (TianLi Aviation Electro-Mechanical Co., Ltd, China) and stained with $1 \%$ Safranin 0 (SigmaAldrich, St. Louis, MO) and 0.5\% Fast Green (Amresco, Solon, $\mathrm{OH}$ ) according to previously reported methods (Jensen, 1962).

Observation and image collection. Singleand multiple-cell origination of somatic embryos was visualized from sections under a light microscope (IX71, Olympus, Tokyo, Japan) equipped with a charge-coupled device camera (SPOT Imaging Solutions, Sterling Heights, MI).

Environmental scanning electron microscope (ESEM) study. Embryonic calli at different developmental stages were examined by ESEM (Quanta 200; FEI, Eindhoven, The Netherlands) in their natural form without additional sample preparation.

\section{Results}

Cytological characteristics of embryonic callus cells. Histologically, embryonic calli 
were composed of two different types of cells. One comprises highly vacuolated cells with a very thin layer of cytoplasmic materials. The other is relatively cytoplasm-rich cells with loosened cytoplasmic materials (Fig. 1A). Somatic embryogenesis was initiated when the embryonic calli were transferred into the mMS medium. Some of the embryonic callus cells were undergoing a cytological transition, which was indicated by cytoplasmic materials' condensation followed by cytoplasm enrichment. During somatic embryo induction, the loosened cytoplasmic materials of some embryonic callus cells (Fig. 1A) gradually gathered to become concentrated (Fig. 1B and C). Subsequently, the cytoplasm of embryonic callus cells became denser and large vacuoles gradually disappeared. In some cases, however, small vacuoles remained visible in the cytoplasm. Finally, these cells became full of thick cytoplasm with a clear nucleus (Fig. 1D) and thus clearly distinguishable from their surrounding cells. These cells in the embryonic calli on the mMS medium were the initial somatic embryo cells.

Pathways of somatic embryo origin. In the initiation stages of somatic embryogenesis, somatic embryos of multiple-cell origin (Fig. 2A and $\mathrm{B}$ ) and single-cell origin (Fig. 3A) were observed. About 55.8\% $(n=86)$ of somatic embryos were derived from the multiple initial somatic embryo cells, whereas $44.2 \%$ were derived from single initial somatic embryo cell. The only difference we noticed is that the somatic embryos derived from the single initial somatic embryo cell are always located inside the embryonic callus, whereas those from the grouped initial somatic embryo cells are often located at the peripheral region of the embryonic calli. Multiple-cell-derived somatic embryos were usually generated at the peripheral region of embryonic calli, where both the outermost and sublayer cells of the embryonic calli could convert into initial somatic embryo cells (Fig. 2A and B). These cells were located in a group and actively dividing. With rapid cell division, the initial somatic embryo cells developed directly into globular somatic embryos. Young globular somatic embryos derived from the initial somatic embryo cells on the outermost layer of calli were soon observed on the surface (Fig. 2C and I). By contrast, a multicellular somatic proembryo formed from the gathered multiple initial somatic embryo cells in the sublayer of embryonic calli was surrounded by a thin layer of normal callus cells in one side and showed some variations in size and morphology (Fig. 2D). Although the somatic proembryos were surrounded by callus cells at the early stage of somatic embryogenesis, they soon enlarged in volume to form a bigger somatic proembryos (Fig. 2E) and then further developed into globular somatic embryos (Fig. 2F). The multiple-cell-derived somatic embryos could be easily observed on the surface of calli through ESEM because they were generated at a high frequency (Fig. 2G-I).

Single-cell-derived somatic embryos were usually generated in the inner part of embryonic calli. The initial somatic embryo

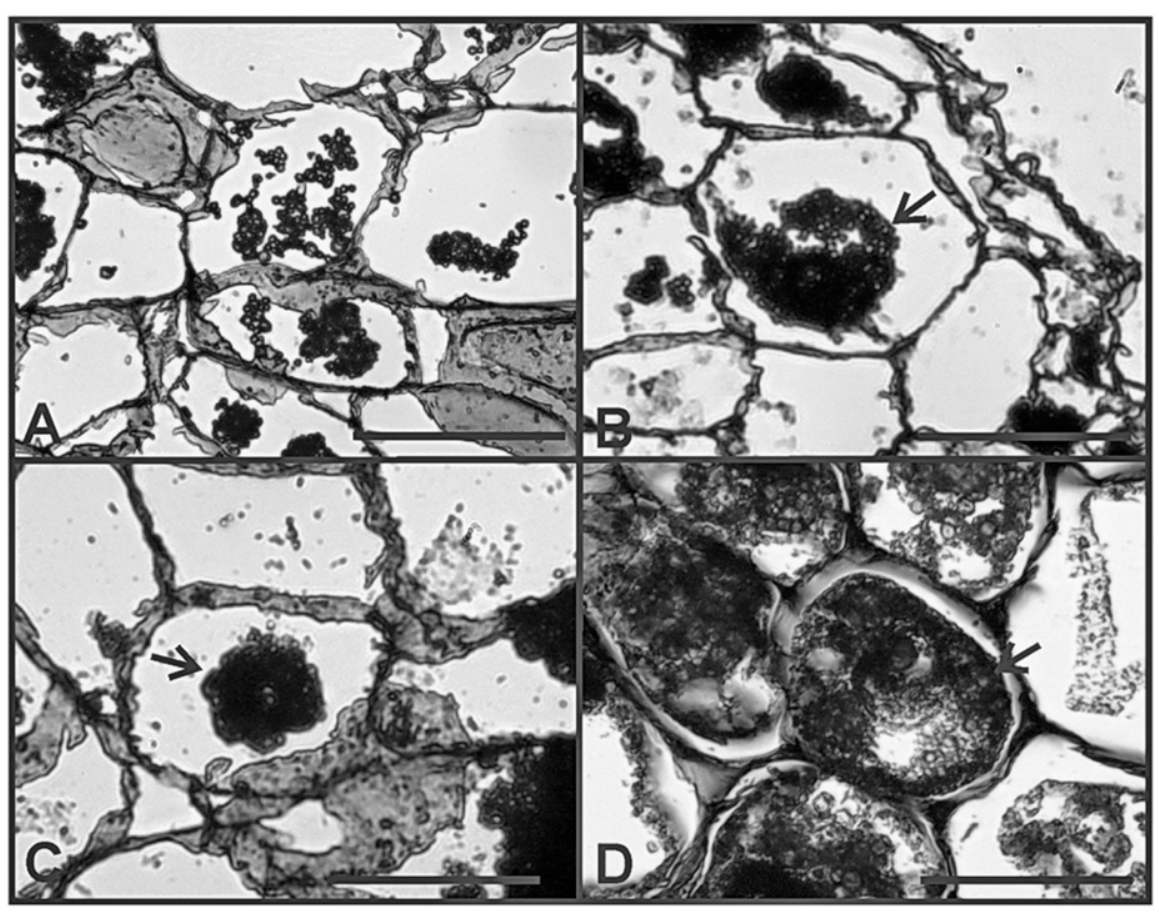

Fig. 1. Cytological characters of embryonic callus cell and initial somatic embryo cell. (A) Embryonic callus cells with loosened cytoplasmic materials. (B and C) Cytoplasmic materials were getting condensed, and a clear denser cytoplasm was formed in some cells (arrow). (D) Initial somatic embryo cells with a denser cytoplasm, clear nuclear and small vacuole (arrow). Bar $=50 \mu \mathrm{m}$. cell was usually elongated and dense in cytoplasm (Fig. 3A). The first division of the initial somatic embryo cell was usually asymmetric and gave rise to two cells of different size (Fig. 3B), a smaller "apical cell" with dense cytoplasm and a larger "basal cell" with some vacuoles, which turned on the development of the somatic proembryo. The larger "basal cell" divided obliquely first (Fig. 3C and D), and the smaller "apical cell" continued to divide longitudinally, resulting in the formation of a four-celled somatic embryo (Fig. 3E). Subsequently, the newly formed additional basal cell divided once, giving rise to a five-celled somatic embryo (Fig. 3F). The number of cells increased without clearly visible expansion of somatic embryo volume until the fivecelled somatic embryo stage. Since then, as the cells divided and somatic embryo grew, it gradually developed into the somatic proembryo just like one in Fig. 2E.

Differentiation of somatic embryos. Somatic embryos that originated from both multiple and single initial somatic embryo cells could develop into globular somatic embryos (Fig. 2C and F). The difference is that somatic embryos from single initial somatic embryo cell usually developed a suspensor-like structure to support the somatic embryo and connected it to the callus cells, which are cone shaped at early stage (Fig. 4A), then developed into pear shaped (Fig. 4B) and subsequently this pear shaped somatic embryos developed into globular stage, whereas an overwhelming majority of those from peripheral regions of embryonic calli directly developed into a globular stage, almost without pear-shaped stage. As the globular somatic embryos differentiated, a concave on the apex could be observed, which are shaped like a cup in a whole and a heart in the section (Figs. 4C). As the cupor heart-shaped somatic embryos developed, the concave gradually disappeared and a dome arose on the apex, which is the promeristem and makes the somatic embryo shaped like a landmine (Fig. 4D). Formation of the dome on the apex indicates the differentiation of somatic embryos, a typical characteristic of orchid embryogenesis (Begum et al., 1994; Chen and Chang, 2000). Subsequently, the dome would develop into a scale leaf and a meristematic region in sequence, and at this stage, the somatic embryos would be called PLBs. This process is similar to the zygotic embryo differentiation (Gilles et al., 1997; Xu et al., 1995), and the PLBs would gradually develop into plantlets.

\section{Discussion}

In orchids, the proembryos are small and protected by a thick seedcoat, which makes experimental manipulation difficult. Furthermore, unlike most of other flowering plants, the embryos of orchids have a long developmental duration (Yeung et al., 1994), which ceases at a very early stage because of the lack of the endosperm (Arditti, 1992). Thus, 


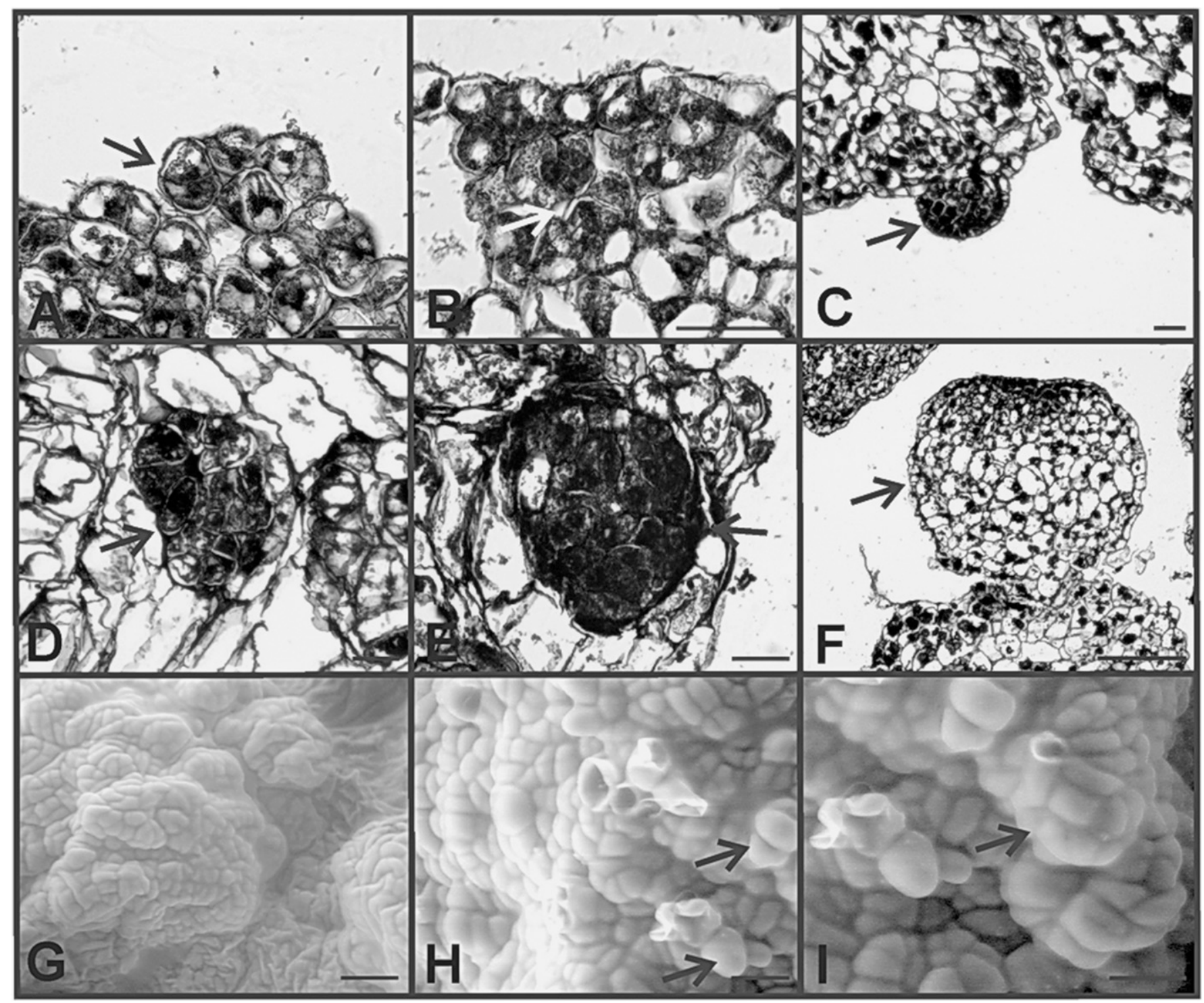

Fig. 2. Development of somatic embryos derived from epidermal layer of embryonic callus. (A) Some of the initial somatic embryo cells on the surface of embryonic callus grouped together (bar $=50 \mu \mathrm{m})$. (B) The initial somatic embryo cells located in the sublayer of embryonic callus gathered together $($ bar $=100 \mu \mathrm{m})$. (C) A young globular somatic embryo on the surface of callus (bar $=50 \mu \mathrm{m})$. (D) A multicellular somatic proembryo formed from the gathered multiple initial somatic embryo cells in the sublayer of embryonic callus $($ bar $=50 \mu \mathrm{m})$. (E) A bigger somatic proembryo developed from the multiple initial somatic embryo cells in the sublayer of embryonic callus is getting ready to stick out (bar $=50 \mu \mathrm{m})$. (F) A globular somatic embryo originated from the multiple initial somatic embryo cells in the sublayer of embryonic callus (bar $=200 \mu \mathrm{m})$. (G-I) Scanning electron microscopic observation on somatic embryo initiation derived from epidermal layer of embryonic callus. (G) The surface of embryonic callus before somatic embryo formation (bar $=100 \mu \mathrm{m})$. $(\mathbf{H})$ Somatic embryos (arrow) on the surface of callus (bar $=100 \mu \mathrm{m})$. (I) A globular somatic embryo (arrow) on the surface of the callus $($ bar $=200 \mu \mathrm{m})$.

the whole process of embryo development in orchids has been poorly understood, and the mechanism of embryo differentiation remains unknown. Elucidating the process of embryo development has been examined using two strategies: rescue of the immature embryo by in vitro culture and development of techniques for somatic embryogenesis. Generally, seed germination of terrestrial orchid species from temperate areas is difficult (Arditti et al., 1982; Rasmussen, 1995). High frequencies of seed germination on medium have been achieved in a limited number of orchid species (Dutra et al., 2007, 2009; Stewart and Kane, 2005, 2006; Tsavkelova et al., 2007). However, the germination of orchid seeds containing an immature embryo is usually time consuming. Meanwhile, plant regeneration via somatic embryogenesis has been established in some orchid species, such as Phalaenopsis (Chen and Chang, 2006; Chung et al., 2006), Cymbidium (Huan et al., 2004), and D. candidum (Zhao et al., 2008), although how the somatic embryos were generated and developed has not yet been clearly elucidated.

In this article, we detailed somatic embryogenesis in $D$. candidum with emphasis on the origin and differentiation of the somatic embryos, which has been virtually unknown. Our observations revealed that somatic embryos would generate from both a single initial somatic embryo cell and a group of the initial somatic embryo cells in the embryonic calli. Notably, the cell division pattern of the single initial somatic embryo cell is comparable to that observed during zygotic embryogenesis (Xu et al., 1995). It first divides into an "apical cell" and a "basal cell" and forms an early somatic proembryo with an obvious suspensor-like structure to support and connect the embryo to the surrounding callus cells (Swamy, 1949).

Furthermore, the division pattern of grouped multiple initial somatic embryo cells is completely different from that of single initial somatic embryo cell because a globular somatic embryo or a multicellular somatic proembryo is directly formed in the outmost surface or the sublayer of embryonic calli. The differences between single and grouped 


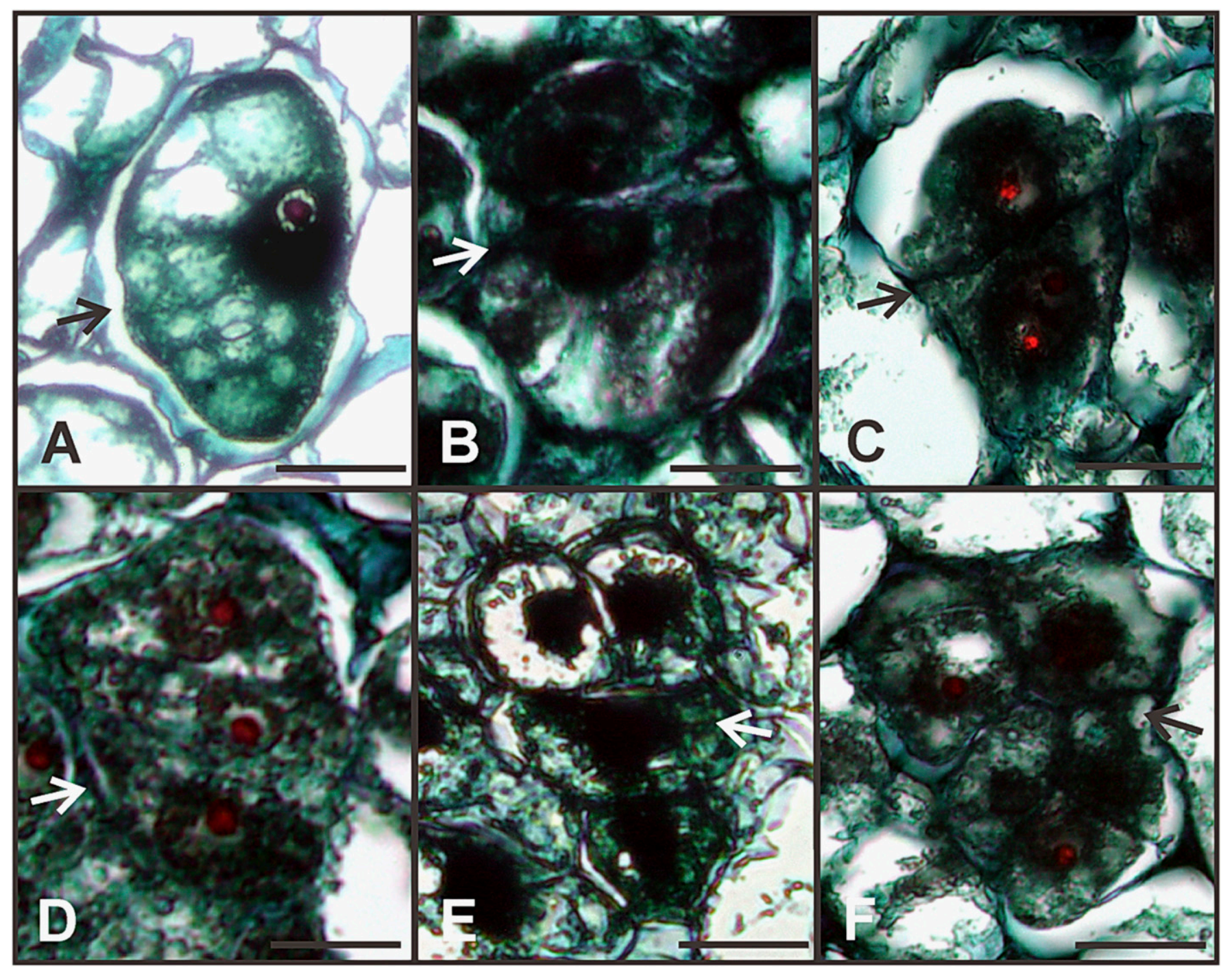

Fig. 3. Cell division pattern of the inner initial somatic embryo cell at the earliest stage of somatic embryogenesis. (A) An initial somatic embryo cell inside the embryonic callus $(\mathrm{bar}=30 \mu \mathrm{m})$. (B) The first cell division of the inner initial somatic embryo cell results in the formation of a smaller "apical cell" and a larger "basal cell" (bar $=30 \mu \mathrm{m})$. (C) The "basal cell" divided earlier than "apical cell" (bar $=50 \mu \mathrm{m})$. (D) A three-celled somatic embryo $($ bar $=50 \mu \mathrm{m})$. $(\mathbf{E})$ A four-celled somatic embryo $(\mathrm{bar}=50 \mu \mathrm{m})$. $(\mathbf{F})$ A five-celled somatic embryo $(\mathrm{bar}=50 \mu \mathrm{m})$.

multiple initial somatic embryo cells are not clear because the cells are cytologically similar but divide in different patterns and form globular somatic embryos using different pathways. It may be worthwhile testing whether the grouped initial somatic embryo cells have the ability for independent embryogenesis and whether the separation of initial somatic embryo cells by surrounding cells play a role in determining their developmental pathways.

Based on our observations, the process of somatic embryogenesis in the orchid can be divided into three stages: initial somatic embryo cell generation, globular somatic embryo formation, and somatic embryo differentiation. In the first stage, some of the embryonic calli cells alter their cell fate to become initial somatic embryo cells. An earlier study reported that the content of the cytoplasm may be the major factor determining the embryonic competence of cells (Nomura and Komamine, 1985). We also noticed that during the cell transition from general calli cells to initial somatic embryo cells, rapid cytoplasm enrichment and devacuolation are the most distinct processes. In fact, cells with dense cytoplasm and large nuclei have been observed in most of the embryonic calli (Jasik et al., 1995), making this a common cellular characteristic for potential embryogenesis. However, not all the cytoplasm-rich cells developed into initial somatic embryo cells, indicating some other requirement exists. In the second stage, globular somatic embryos formed through two pathways, which showed similar morphology and finally emerged out of the calli. In general, globular somatic embryos originated from grouped initial somatic embryo cells appeared to fuse with parental tissue over a broad area, whereas those from a single-cell origin were more likely to be attached by a narrow suspensorlike organ (Maheswaran and Williams, 1985). At somatic embryo differentiation stage, the main characteristic is the formation of PLB, which is similar to the process by which the seeds germinate into protocorms on a culture medium (Ye and Cheng, 1988). The formation of the protocorm is considered to be a peculiarity of postseminal development in orchids. PLBs were first obtained from shoot tips of Cymbidium hookerianum and were considered to be somatic embryos in orchids (Begum et al., 1994; Ishii et al., 1998). With development of the globular somatic embryo, it differentiated into a cup- or heart-shaped one, followed by the differentiation into a landmineshaped somatic embryo and PLB with promeristem and then into intact plantlets (Ye and Cheng, 1988). Thus, the process of somatic embryogenesis is similar to zygotic embryogenesis, suggesting that such a system can be a useful model to study the mechanisms of orchid embryogenesis. Furthermore, this culture system combined with laser dissection may be capable of isolating all plant materials, 


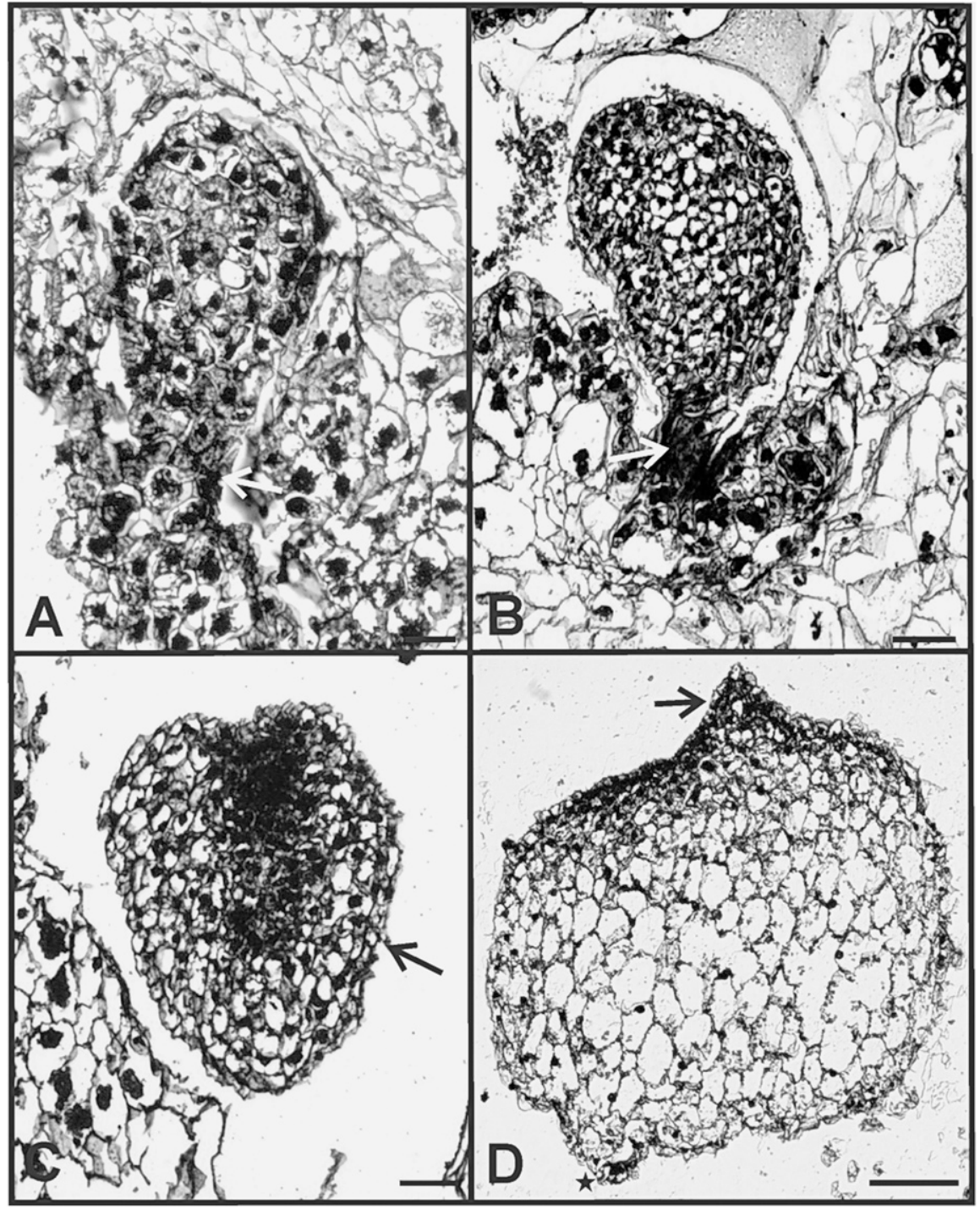

Fig. 4. Somatic embryo differentiation. (A) A cone-shaped somatic proembryo with a suspensor-like structure within callus $($ bar $=100 \mu \mathrm{m})$. (B) Pear-shaped somatic embryo generated inside the embryonic callus would develop into a globular somatic embryo and stick out of the callus before the differentiation stage $(\mathrm{bar}=200 \mu \mathrm{m})$. (C) A cup- or heart-shaped somatic embryo differentiated from a globular somatic embryo $(\mathrm{bar}=250 \mu \mathrm{m})$. (D) A landmine-shaped somatic embryo with promeristem (arrow) and a rhizoid (star) $(\mathrm{bar}=500 \mu \mathrm{m})$.

from a single initial somatic embryo cell to mature somatic embryo, for molecular and biochemical analyses.

\section{Literature Cited}

Arditti, J., M.A. Clements, G. Fast, G. Hadley, G. Nishimura, and R. Ernest. 1982. Orchid seed germination and seedling culture a manual, $\mathrm{p}$. 243-370. In: J. Arditti (ed.). Orchid biologyreviews and perspectives II. Cornell University Press, Ithaca, NY.

Arditti, J. 1992. Fundamentals of orchid biology. Wiley, New York, NY.

Begum, A.A., M. Tamaki, M. Tahara, and S.J. Kako. 1994. Somatic embryogenesis in Cymbidium through in vitro culture of inner tissue of protocorm-like bodies. J. Jpn. Soc. Hort. Sci. 63:419-427.

Chen, J.T. and W.C. Chang. 2000. Efficient plant regeneration through somatic embryogenesis from callus cultures of Oncidium (Orchidaceae). Plant Sci. 160:87-93.
Chen, J.T. and W.C. Chang. 2006. Direct somatic embryogenesis and plant regeneration from leaf explants of Phalaenopsis amabilis. Biol. Plant. 50:169-173.

Chung, J.D., H.Y. Kim, J.H. Suh, O.C. Kwon, and C.K. Kim. 2006. Direct somatic embryogenesis from thin-section leaf explant of Phalaenopsis hybrids. HortScience 41:1066-1067.

Dutra, D., M.E. Kane, and L. Richardson. 2009. Asymbiotic seed germination and in vitro seedling development of Cyrtopodium punctatum: A propagation protocol for an endangered Florida native orchid. Plant Cell Tissue Organ. Cult. 96:235-243.

Dutra, D., S.L. Stewart, J. Kauth, T.R. Johnson, N. Philman, M.E. Kane, and L. Richardson. 2007. Asymbiotic seed germination of the threatened orchid Bletia puipurea in Florida. In Vitro Cell. Dev. Biol. Anim. 43:S45.

Gilles, L., B. Denis, and V. Joachim. 1997. Morphogenesis of the protocorm of Cypripedium acaule (Orchidaceae). Plant Syst. Evol. 205:53-72.

Higashi, K., H. Shiota, and H. Kamada. 1998 Patterns of expression of the genes for glutamine synthetase isoforms during somatic and zygotic embryogenesis in carrot. Plant Cell Physiol. 39:418-424.

Huan, L.V., T. Takamura, and A. Tanaka. 2004. Callus formation and plant regeneration from callus through somatic embryo structures in Cymbidium orchid. Plant Sci. 166:1443-1449.

Huang, B.Q., X.L. Ye, E.C. Yeung, and S.Y. Zee 1998. Embryology of Cymbidium sinense: the microtubule organization of early embryos. Ann. Bot. 81:741-750.

Ikeda-Iwai, M., S. Satoh, and H. Kamada. 2002. Establishment of a reproducible tissue culture system for the induction of Arabidopsis somatic embryos. J. Expt. Bot. 53:1575-1580.

Ishii, Y., T.M. Takamura, M. Goi, and M. Tanaka. 1998. Callus induction and somatic embryogenesis of Phalaenopsis. Plant Cell Rpt. 17:446-450.

Jasik, J., T. Salajova, and J. Salaj. 1995. Developmental anatomy and ultrastructure of early somatic embryos in European black pine (Pinus nigra Arn.). Protoplasma 185:205-211.

Jensen, W.A. 1962. Botanical histochemistry. Freeman, San Francisco, CA.

Lee, E.K., D.Y. Cho, and W.Y. Soh. 2001. Enhanced production and germination of somatic embryos by temporary starvation in tissue cultures of Daucus carota. Plant Cell Rpt. 20:408-415.

Li, Y., C.L. Wang, S.X. Guo, J.S. Yang, and P.G. Xiao. 2008. Two new compounds from Dendrobium candidum. Chem. Pharm. Bull. (Tokyo) 56:1477-1479

Li, Y., C.L. Wang, Y.J. Wang, S.X. Guo, J.S. Yang, X.M. Chen, and P.G. Xiao. 2009a. Three new bibenzyl derivatives from Dendrobium candidum. Chem. Pharm. Bull. (Tokyo) 57:218-219.

Li, Y., C.L. Wang, Y.J. Wang, S.X. Guo, J.S. Yang, X.M. Chen, and P.G. Xiao. 2009b. Four new bibenzyl derivatives from Dendrobium candidum. Chem. Pharm. Bull. (Tokyo) 57:997-999.

Luo, Y. and H.U. Koop. 1997. Somatic embryogenesis in cultured immature zygotic embryos and leaf protoplasts of Arabidopsis thaliana ecotypes. Planta 202:387-396.

Maheswaran, G. and E.G. Williams. 1985. Origin and development of somatic embryoids formed directly on immature embryos of Trifolium repens in vitro. Ann. Bot. 56:619-630.

Meneses, A., D. Flores, M. Munoz, G. Arrieta, and A.M. Espinoza. 2005. Effect of 2,4-d, hydric stress and light on indica rice (Oryza sativa) somatic embryogenesis. Rev. Biol. Trop. 53: 361-368.

Nagmani, R., M.R. Becwar, and S.R. Wann. 1987. Single-cell origin and development of somatic embryos in Picea abies (L.) Karst. (Norway spruce) and P. glauca (Moench) Voss (white spruce). Plant Cell Rpt. 6:157-159.

Nishiwaki, M., K. Fujino, Y. Koda, K. Masuda, and Y. Kikuta. 2000. Somatic embryogenesis induced by the simple application of abscisic acid to carrot (Daucus carota L.) seedlings in culture. Planta 211:756-759.

Nomura, K. and A. Komamine. 1985. Identification and isolation of single cells that produce somatic embryos at a high frequency in a carrot suspension culture. Plant Physiol. 79:988-991.

Raval, M. and B.B. Chattoo. 1993. Role of media constituents and proline in callus growth, somatic embryogenesis and regeneration of Oryza sativa cv Indica. Indian J. Expt. Biol. 31:600-603.

Rasmussen, H.N. 1995. Terrestrial orchids from seed to mycotrophic plant. Cambridge University Press, New York, NY

Shiau, Y.J., S.M. Nalawade, C.N. Hsia, V. Mulabagal, and H.S. Tsay. 2005. In vitro propagation of the Chinese medicinal plant, Dendrobium candidum Wall. Ex Lindl., from axenic nodal 
segments. In Vitro Cell. Dev. Biol. Plant 41:666-670

Stewart, S.L. and M.E. Kane. 2005. In vitro seed germination and seedling development of Habenaria mocroceratitis, an endangered terrestrial orchid. In Vitro Cell. Dev. Biol. Anim. 41:27a.

Stewart, S.L. and M.E. Kane. 2006. Asymbiotic seed germination and in vitro seedling development of Habenaria macroceratitis (Orchidaceae), a rare Florida terrestrial orchid. Plant Cell Tissue Organ. Cult. 86:147-158.

Swamy, B.G.L. 1949. Embryological studies in the Orchidaceae. II. Embryology. Amer. Midl. Nat. 41:184-201.

Tsavkelova, E.A., T.A. Cherdyntseva, S.Y. Klimova, A.I. Shestakov, S.G. Botina, and A.I. Netrusov. 2007. Orchid-associated bacteria produce indole-3-acetic acid, promote seed germination, and increase their microbial yield in response to exogenous auxin. Arch. Microbiol. 188:655-664.

Williams, E.G. and G. Maheswaran. 1986. Somatic embryogenesis: factors influencing coordinated behaviour of cells as an embryogenic group. Ann. Bot. 57:443462.

Xu, Z.Y., C.Y. Yang, and M.X. Yang. 1995. Studies on the double fertilization and embryogeny in Dendrobium candidum Wall. ex Lindl. Journal of Tropical and Subtropical Botany (China) 3:60-64.

Ye, X.L. and S.J. Cheng. 1988. Morphology of immature seeds and development in vitro of Dendrobium candidum. Acta Bot. Yunnanica 10:285-290.

Ye, X.L. and J.Y. Guo. 1995. Female gametophyte development and embryogeny in Cymbium sinense (Andr.) Willd. Journal of Tropical and Subtropical Botany (China) 3:54-58.
Ye, X.L., S.Y. Zee, and E.C. Yeung. 1997. Suspensor development in the nun orchid, Phaius tankervilliae. International Journal of Plant Sciences 158:704-712.

Yeung, E.C., S.Y. Zee, and X.L. Ye. 1994. Embryology of Cymbidium sinense: Ovule development. Phytomorphology 44:55-63.

Zhao, P., W. Wang, F.S. Feng, F. Wu, Z.Q. Yang, and W.J. Wang. 2007. High-frequency shoot regeneration through transverse thin cell layer culture in Dendrobium candidum Wall Ex Lindl. Plant Cell Tissue Organ. Cult. 90:131-139.

Zhao, P., F. Wu, F.S. Feng, and W.J. Wang. 2008. Protocorm-like body (PLB) formation and plant regeneration from the callus culture of Dendrobium candidum Wall ex Lindl. In Vitro Cell. Dev. Biol. Plant 44:178-185.

Zimmerman, J.L. 1993. Somatic embryogenesis: A model for early development in higher plants. Plant Cell 5:1411-1423. 